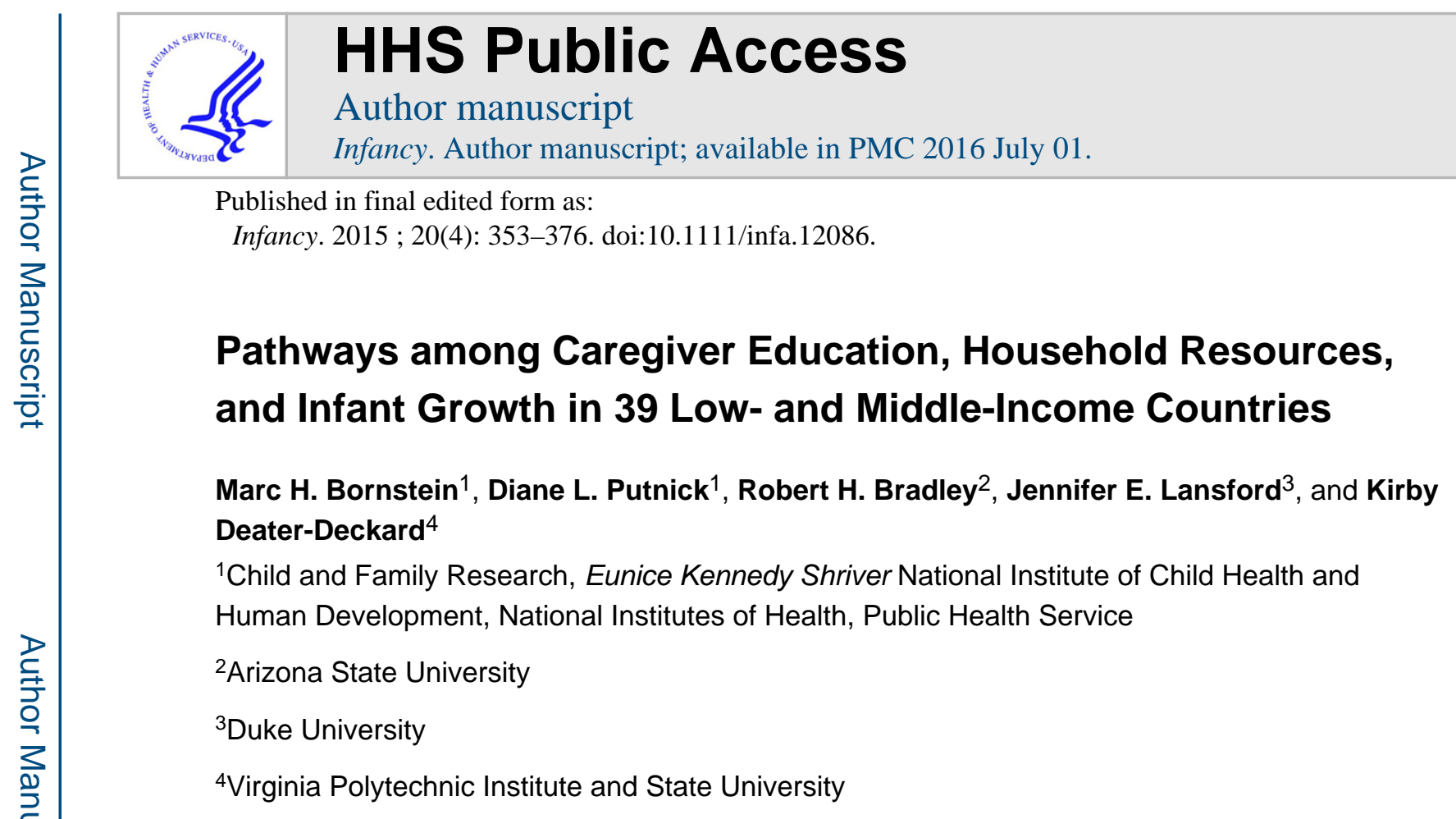

\begin{abstract}
Caregiver education is known to relate to the growth of children, but possible mediation mechanisms of this association are poorly characterized and generally lack empirical support. We test whether instructional capital (caregiver education) leads to improved infant growth through availability of physical capital (household resources) across a wide swath of low- and middleincome countries (LMIC). Using the Multiple Indicator Cluster Survey (MICS3), we explore relations among caregiver education, household resources, and infant ( $M$ age $=.99$ years) growth in 117,881 families living in 39 LMIC. Overall, household resources mediated $76 \%$ of the small association between caregiver education and infant growth. When disaggregated by countries characterized by low, medium, and high levels of human development (as indexed by average life expectancy, education, and gross domestic product), household resources mediated $48 \%$ to $78 \%$ of the association between caregiver education and infant growth. Caregiver education had effects on infant growth through household resources in countries characterized by low, medium, and high levels of human development; for girls and boys; and controlling for indexes of infant feeding and health.
\end{abstract}

\title{
Keywords
}

infant growth; caregiver education; household resources

Poverty is associated with low caregiver education and multiple disadvantaged physical conditions, such as inferior sanitation and hygiene that affect child growth (Bartlett \& Minujin, 2009). Among the many factors that determine child thriving, caregiver education (instructional capital) and household resources (physical capital) are prominent (Walker et

Address correspondence to: Dr. Marc H. Bornstein, Child and Family Research, Eunice Kennedy Shriver National Institute of Child Health and Human Development, Suite 80306705 Rockledge Drive, Bethesda MD 20892-7971 USA, TEL: 301-496-6832, FAX: 301-496-2766, Marc_H_Bornstein@nih.gov. 
al., 2007). How are these factors associated with the promotion or inhibition of infant growth in the developing world?

\section{Infant Growth}

In 2012, an estimated 162 million infants and children under 5 years of age were affected by moderate or severe stunting (short height for age; UNICEF/WHO/World Bank, 2013) and 51 million suffered from wasting (low weight for height; Black et al., 2013). More than 1 in 5 children will likely be stunted in 2020. Infant stunting and wasting therefore constitute major public health challenges of the $21^{\text {st }}$ century, particularly in LMIC. Infant stunting, wasting, and intrauterine growth restriction are responsible for 2.2 million deaths and $21 \%$ of disability-adjusted life-years lost among infants and children younger than 5 years (Black et al., 2008). Millennium Development Goal (MDG) Target 1C (United Nations, 2013), to halve the prevalence of undernourished infants and children, was established with these ominous statistics in mind. MDGs focus on valorizing human capital, improving infrastructure, and increasing social, economic, and political rights, with a strong emphasis on increasing basic standards of living. The first years of life are critical for the prevention of growth problems (Victoria, de Onis, Hallal, Blössner, \& Shrimpton, 2010). Moreover, growth problems in early life have long-term consequences, which include short adult height and reduced intellectual development and economic productivity (Victora et al., 2008). Variance in fetal growth, most commonly indexed by birth weight, affects lifespan brain development (Walhovd et al., 2012). Because factors contributing to growth problems in early childhood tend to persist, and because of their collateral damage to other biological systems, growth retardation in infants and young children often anticipates difficulties in their cognitive processing and eventually school achievement.

\section{Caregiver Education}

In the first years of life, mothers are primary caregivers to their children and customarily custodians of the household (Bornstein, 2015). Maternal education is regularly associated with important parenting beliefs and behaviors; for example, more educated parents spend more time with their children, possess more knowledge about childrearing and child development, and have more knowledge about factors that reduce the risks of illness and home practices to improve health (Bornstein, Hahn, Suizzo, \& Haynes, 2001; Guryan, Hurst, \& Kearney, 2008). In LMIC, maternal education, net of other family socioeconomic indicators, is positively related to mothers' own health care utilization as well as the nutritional status and health care utilization for her children (Abuya, Ciera, \& KimaniMurage, 2012; Ahmed, Creanga, Gillespie, \& Tsui, 2010; Burchi, 2012). Maternal education has significant effects on birth weight and gestational age (Currie \& Moretti, 2003). In short, the positive characteristics of caregiver (especially maternal) education vis-à-vis infant and child development are profound and pervasive.

Unfortunately, in many LMIC, instructional capital in the form of maternal education is limited. Of the 39 LMIC reported on in this study with available data $(n=28)$, the median years of education for women aged 25 and over was only 5.17 in 2010 , with a low of 0.75 years in Mozambique and a high of only 11.22 years in Ukraine (Barro \& Lee, 2013). 
What mechanisms link maternal education to infant growth? To date, possible pathways are poorly characterized (Frost, Forste, \& Haas, 2005). One possibility, which we explore here, is that better educated parents provide safer and more stimulating home environments for their infants.

\section{Household Resources}

Just as there is reason to believe that education increases the likelihood parents will make better choices pertaining to health care utilization, there is reason to believe that better educated parents also acquire and utilize other resources that have implications for their infants' health and growth.

Infant health and growth seem especially sensitive to physical conditions present in the infant's environment (Leventhal \& Newman, 2010). Unfortunately, high percentages of households in LMIC lack basic household resources, including internal facilities (e.g., water, toilets, cooking facilities, refrigeration), structural materials used in housing (e.g., flooring), and household items (transportation, radio, TV, telephone, books, toys). When water does not come directly into the house, contamination from bacteria and parasites is commonplace, resulting in diarrhea and malnutrition, and contaminated water is a disease source that can retard infant and child growth (Halpenny, Koski, Valdes, \& Scott, 2012; Yongsi, 2010). WHO estimates that water contaminants account for $6 \%$ of all disease burden in infants and young children. MDG Target 7C-to halve the proportion of the population without sustainable access to safe drinking water and basic sanitation-remains unmet. Fecal-oral spread of bacterial pathogens, resulting from lack of access to appropriate toilets, contributes to diarrhea, intestinal infestations, and/or environmental enteropathy (intestinal inflammation, changes in the intestinal villi, and reduced absorptive capacity), all of which contribute to infant and child growth problems. Poor food storage facilities constitute another major problem for infant and child growth and health (Hong, Banta, \& Betancourt, 2006; Motarjemi, Käferstein, Moy, \& Quevedo, 1993). When homes lack adequate facilities, food is often left out for later consumption, increasing the likelihood of contamination (Bartlett, 2003). Poor home construction also undermines growth and health in infants and children (Hong et al., 2006). For example, poor ventilation (often associated with inadequate flooring, wall composition, and roofing) is connected to poor indoor air quality and increased respiratory illnesses. An open stove with no chimney increases indoor pollutants and overall illness rates in family members (Herrin, Amaral, \& Balihuta, 2012). Research has shown that doing something as simple as replacing a dirt floor with a concrete floor can have noticeable impacts on the health and cognitive development in young children (Cattaneo, Galiani, Gertler, Marinez, \& Titiunik, 2007). About 1.3 billion people lack predictable access to electricity (International Energy Agency, 2012). Having electricity reduces mortality in infants and children under age 5 in LMIC (Wagstaff, Bustreo, Bryce, Claeson, \& the WHO-World Bank Child Health and Poverty Working Group, 2004). Transportation allows both adults and children access to resources that may be available only outside their dwelling. Finally, there is evidence from LMIC that stimulation in the home is associated with children's height and nutritional status as many households in LMIC have few formal materials to stimulate children's learning (Holding, 2003; Wachs, 2008). 


\section{The Human Development Index}

In this analysis we organized data from 39 LMIC by the Human Development Index (HDI; UNDP, 2008). The HDI was developed by the United Nations to measure social and economic status of a country. The HDI has three major components: life expectancy (in years), education (composed of the adult literacy rate and the percentage of school-aged children enrolled in primary, secondary, and tertiary school), and gross domestic product (GDP; in purchasing power parity [PPP] in U.S. dollars). The HDI is rooted in a development paradigm that focuses on human growth and the role of environments to support the development of human potential. The HDI therefore offers a proxy for the level of support that is generally available to promote human development. As such, it connects to many physical and social aspects of the family and home environment with known relations to infant and child well-being. Given its underlying ethos and aims, we organized countries into the standard bottom three HDI groups that apply to LMIC (i.e., excluding very high HDI) and tested models of association among caregiver education, household resources, and infant growth at different levels of country HDI. These analyses were designed to illuminate how broad or circumscribed are presumed universal pathways toward infant growth.

\section{Infant Gender}

Prior research suggests that infant gender plays a role in how infants are treated (Ruble, Martin, \& Berenbaum, 2006; Wilcox \& Kline, 2013), and it is widely believed that infant girls and boys are reared differently in most parts of the world. Limited financial, material, and social resources may induce parents to engage in more gender-based differential treatment in LMIC. Contexts of childrearing are normally gendered and may have consequences for infant growth. Consequently, we also separately explored relations among caregiver education, household resources, and growth in young girls and boys.

\section{This Study}

Inadequate household resources as represented in instructional and physical capital underlie growth problems in children. In LMIC where household facilities and access to material resources are generally meager, even small differences in available resources may loom large for children's growth. Here we explored one prominent pathway of association from caregiver education to infant growth through household resources, and we did so in 39 LMIC around the world. In these analyses, we controlled for child feeding practices and health to exclude two proximal factors that might also explain variation in infant growth; and we compared pathways in countries scoring low, medium, and high in human development and in girls and boys. We expected that caregiver provision of household resources might at least partially mediate associations between caregiver education and infant growth. 


\section{Methods}

\section{Participants}

Families with an infant 0 through 2 years of age $(N=117,881)$ were recruited from 39 LMIC (Table 1). If the family had more than one child younger than 3 , a single child was randomly selected from the family for inclusion in this study. Target children averaged .99 years of age $(S D=.82)$, and $48.8 \%$ were female. Most $(99.5 \%)$ primary caregivers were female, $M=28.45$ years of age $(S D=7.84)$. The countries that are the principal subject of investigation all constitute developing nations (UNICEF, 2006) defined with reference to the World Bank's system of classification of economies based on gross national incomes per capita, quality of life (life expectancy, literacy rates), and economic diversification (labor force, consumption).

\section{Procedures}

This study used data from the third round of the Multiple Indicator Cluster Survey (MICS3; UNICEF, 2006). Informed consent was obtained from all participants, and research ethics followed the laws in each country. Each country designed and selected a national probability sample and field implemented the MICS between 2005 and 2010 with minimum deviation from an overall standard design. A three-stage sampling frame was used: (1) primary sampling units (PSUs) were defined, if possible, as census enumeration areas, and they were selected with systematic probability proportionate to size (pps); (2) segments (clusters) were targeted; and (3) households were selected within each segment that were to be interviewed in the survey. To foster simple implementation, implicit stratification was followed. When this form of geographic stratification is used together with pps sampling, the sample proportionately distributes into each of a nation's administrative subdivisions.

Caregiver education was derived from the education module of the MICS Household Questionnaire. Household resources questions pertaining to quality of housing, material resources, and learning resources were taken from the water and sanitation and household characteristics modules of the Household Questionnaire and the child development module of the Questionnaire for Children Under Five. Child growth indicators were derived from the anthropometry module of the Questionnaire for Children Under Five and followed World Health Organization (WHO) Growth Standards (WHO, 2006). Covariates were drawn from the breastfeeding and care of illness modules of the Questionnaire for Children Under Five. MICS3 questionnaires are available at http://www.childinfo.org/ mics3_questionnaire.html.

Caregiver education-The head of the household (who was often also the child's primary caregiver) was asked about the highest school grade level completed for all household members. Grade levels are not comparable across countries, so primary caregiver education was coded into categories: $0=$ none or only preschool, $1=$ primary school, $2=$ secondary school, or 3 = higher education. Hence, the education level does not necessarily imply that all grades in the category were completed, only that the highest grade completed was within the category. 
Household resources-Following guidelines specified in the WHO and UNICEF (2008) drinking water ladder, drinking water was coded into three categories: unimproved ( $1=$ unprotected springs or wells, tanker-trucks or carts with a small tank/drum, or surface water), improved ( $2=$ public taps or standpipes, tube wells or boreholes, protected wells or springs, or rainwater collection), and piped ( $3=$ piped directly to the household dwelling, plot, or yard). Following the WHO and UNICEF's sanitation ladder (WHO \& UNICEF, 2008), toilet facilities were coded into four categories: open defecation $(1=$ no facilities or toileting in the bush or field), unimproved ( 2 - pit latrines without a slab or platform, hanging latrines, and bucket latrines), shared improved (3), and unshared improved (4). Improved facilities included flush or pour-flush latrines, ventilated improved pit (VIP) latrines, pit latrines with slabs, and composting toilets. The main material of the dwelling floor was recoded into three superordinate categories of natural (1), rudimentary (2), and finished flooring (3). Cooking was recoded into whether household cooking was done on an open fire or stove (0) or in a closed stove (1). Finally, the presence (1) or absence (0) of refrigeration in the household was recorded. A Quality of Housing Index (Bradley \& Putnick, 2012) was computed as the standardized average of drinking water, toilet facilities, household flooring, cooking, and refrigeration. Higher scores on this index indicated a healthier and safer home environment for children.

Nine household items (radio, TV, mobile telephone, non-mobile telephone, electricity, motorcycle or scooter, animal-drawn cart, car or truck, and boat with motor) were coded as absent (0), or present (1). Mobile and non-mobile telephone were recoded into a single item to indicate the absence (0) or presence (1) of either type of telephone in the household. Four items about household transportation - motorcycle or scooter, animal-drawn cart, car or truck, and boat with a motor - were recoded into a single item to indicate the absence ( 0 ) or presence (1) of any kind of transportation not powered by humans. A Material Resources Index (Bradley \& Putnick, 2012) was computed as the sum of the presence of a radio, TV, telephone, non-human-powered transportation, and electricity in the household. Higher scores on this index indicated the availability of a broader range of experiences for children.

The numbers of adult books and children's books in the household were recoded into three categories to indicate no books (0), 1-9 books (1), 10 or more books (2). Store-bought toys were coded as ( 0 ) child does not play with the item or (1) child plays with the item. These 3 items were standardized and averaged to form an index of Learning Resources (Bradley \& Putnick, 2012). Higher scores on this index indicated the availability of more cognitive stimulation opportunities for children.

Infant growth-Trained administrators weighed and measured infants using standard equipment and a common WHO protocol (UNICEF, 2012). Using the resulting weight and length/height data, we adapted and implemented the WHO's Child Growth Standards SPSS macro. This macro uses standard data files to calculate $z$-scores for height-for-age and weight-for-height based on WHO Child Growth Standards (WHO, 2006; WHO \& UNICEF, 2009) for typically developing, healthy infants from a variety of backgrounds. Low heightfor-age most often reflects prolonged undernutrition. Low weight-for-height is generally indicative of an acute recent weight loss, due either to starvation or serious illness (WHO, 1997). 
Covariates-The criteria we followed for appropriate feeding were: (1) exclusive breastfeeding for infants under 6 months, (2) continued breastfeeding and 2 or more meals per day for infants aged 6 to 8 months, (3) continued breastfeeding and 3 or more meals per day for infants aged 9 to 11 months, and (4) 3 or more meals per day for infants 12 months and older. Although the WHO recommends continued breastfeeding through 24 months (WHO, 2002), MICS data showed that 27\% fewer infants were breastfed between ages 12 and 24 months than between ages 6 and 12 months. MICS data also showed that some of those infants were being fed 3 or more meals a day consisting of solid food, and we did not want to penalize cases where infants of 12 months were being fed an appropriate number of solid meals just because they were no longer being breastfed. The indicator of health was diarrhea, defined by the MICS as 3 or more loose, watery, or bloody stools per day. We chose diarrhea as an indicator of health because it has been directly linked to infant and child stunting (Checkley et al., 2008). Both variables were coded as $0=$ No, $1=$ Yes.

Human development-The countries in this study were organized according to the Human Development Index (UNDP, 2008). The HDI ranges from 0.00 to 1.00, and countries with an HDI of 0.90 to 1.00 are considered very high, 0.80 to 0.89 are considered high, 0.50 to 0.79 medium, and 0.00 to 0.49 low. Because the MICS3 data were collected between 2005 and 2010, we used the 2008 HDI (UNDP, 2008), which is based on 2006 data. Our focus on LMIC limits countries we included to those ranking high, medium, and low on the HDI.

\section{Aims and Analytic Plan}

To evaluate associations between caregiver education and infant growth through household resources, we employed path analysis as implemented in Mplus version 7.2 (Muthén \& Muthén, 2012). In all models, full information maximum likelihood (FIML; Arbuckle, 1996) within Mplus was used to account for missing data (11.58\% of the data points were missing). All countries collected information about caregiver education, quality of housing, and material resources. Some countries did not ask questions about books and toys or collect child weight and height/length, so more data were missing for these variables. Countries with missing data were distributed among low, medium, and high HDI groups. A model was considered to have good fit if the CFI and TLI $>0.95$, the RMSEA $<0.06$, and the SRMR $\leq$ 0.08 (Hu \& Bentler, 1999; Marsh, Balla, \& Hau, 1996). Standardized path coefficients are presented.

First, we tested saturated models with education directly associated with infant growth (as indexed by height-for-age and weight-for-height scores) to determine the magnitude of any direct association between the two. Next, we tested 2 models with education associated with household resources (quality of housing, material resources, and learning resources), and household resources associated with infant height-for-age and weight-for-height scores. In this second model the direct path from caregiver education to infant growth was omitted, and model fit and modification indices were evaluated to determine whether the direct path was warranted. We also evaluated the indirect association between caregiver education and infant growth to determine whether household resources mediated that association. Mediation was assessed by comparing the size of the unstandardized indirect effect with the 
unstandardized direct effect in the model without the mediator and by the absence of a direct effect in the model with all three terms (MacKinnon, 2008). The indirect effect was computed using the delta method within Mplus (Muthén \& Muthén, 2012). We did not use the traditional criterion of a nonsignificant $\chi^{2}$ test for the main models (although to be consistent with the literature we report it), or nonsignificant change in chi-square $\left(\Delta \chi^{2}\right)$ for two nested models, because the $\chi^{2}$ value is known to be sensitive to sample size (Cheung \& Rensvold, 2002). Given the very large sample in this study, we used alternative fit indices as noted above, and change in CFI values $(\Delta \mathrm{CFI}<0.01)$ for multiple group models because these indices are not sensitive to sample size (Cheung \& Rensvold, 2002). We then added infant feeding and health to the model to determine whether the association between education and infant growth through household resources remained strong when accounting for these variables. Finally, we evaluated multiple group models to determine whether model parameters were similar for low-, medium-, and high-HDI countries and for girls and boys. We did not compute the models separately for each country for several reasons: (1) the sample sizes vary greatly by country, (2) computing a multiple group model by 39 countries taxes the data, even for a large sample, and (3) it would be nearly impossible to meaningfully discuss differences across 39 disparate countries.

\section{Results}

\section{Descriptives and Correlations}

Descriptive statistics for study variables by HDI group are presented in Table 2, which also includes bivariate correlations among study variables. Overall, the average level of education across all 39 countries was the equivalent of primary school $(M=1.11, S D=.93)$. Averaged across countries, infants scored about one-third of a $S D$ below average on heightfor-age $(M=-.34, S D=.66)$ and average on weight-for-height $(M=.00, S D=.84$; WHO, 2006), but infant growth was worse in lower-HDI countries and better in higher-HDI countries. Correlations among study variables varied by HDI group.

\section{Path Analyses}

In path analyses with caregiver education associated with infant height-for-age, the standardized path coefficient was $0.18, p<0.001$, and for weight-for-height, the standardized path coefficient was $0.19, p<0.001$. To determine whether household resources mediate the relation between caregiver education and infant growth, we fit two models with education associated with household resources (quality of housing, material resources, and learning resources), and household resources associated with infant growth (height-for-age and weight-for-height). The three household resources were allowed to covary. Fit was excellent for both models (Figure 1) as indicated by CFI and TLI values close to 1.00, and RMSEA and SRMR values close to 0. Caregiver education had large, positive associations with all 3 household resources, which in turn had small associations with infant growth (except for the effect of material resources on weight-for-height, which was near 0 ). The standardized coefficients for the total indirect effect of caregiver education on infant growth through the 3 household resources were $0.14, p<0.001$, for both infant height-for-age and infant weight-for-height. Household resources, taken together, mediated $76 \%$ of the direct association between caregiver education and infant height-for-age as well 
as infant weight-for-height (indirect effect/total direct effect; MacKinnon, 2008; Shrout \& Bolger, 2002).

Next, we added infant feeding and health to the models. These covariate models included paths from caregiver education to feeding and health and paths from feeding and health to infant growth. With feeding and health in the models, the paths between caregiver education and household resources, and between household resources and infant growth, did not change compared to the model without these controls (the unstandardized coefficients differed by .008 or less), indicating that caregiver education was associated with household resources which were associated with infant growth, independent of whether their infant was being fed according to WHO guidelines and whether the infant had diarrhea in the past 2 weeks.

\section{Multiple Group Models}

We next explored whether the models in Figure 1 fit equally well for infants in low- ( $n=$ $45,430)$, medium- $(n=60,679)$, and high-HDI $(n=11,772)$ countries and for girls $(n=$ $57,527)$ and boys $(n=60,350)$. For HDI groups, we compared a model with no equality constraints across the 3 groups with a model with equality constraints on path coefficients. The differences in CFI values were 0.049 for both the infant height-for-age and infant weight-for-height models, indicating that one or more of the paths differed in the three groups. Releasing paths between (1) caregiver education and quality of housing in all 3 groups, (2) caregiver education and material resources in high-HDI countries, and (3) caregiver education and learning resources in low-HDI countries brought the changes in model fit to an acceptable level, $\Delta \mathrm{CFI}=0.007$ for both models. The standardized path coefficients between caregiver education and all 3 indicators of household resources were positive and significant in all 3 groups (Figure 2). The path coefficients from household resources to height-for-age were all small but significant. The path coefficients from household resources to weight-for-height were also small and near 0 for material resources in all 3 groups and quality of housing in high-HDI countries. Next, we compared the direct effects between caregiver education and infant growth to indirect effects mediated through household resources in the 3 HDI groups in unconstrained models. For infant height-for-age, $49 \%$ of the direct association was mediated through household resources in low-HDI countries, $78 \%$ in medium-HDI countries, and $54 \%$ in high-HDI countries. For infant weight-for-height, $48 \%$ of the direct association was mediated through household resources in low-HDI countries, $65 \%$ in medium-HDI countries, and 72\% in high-HDI countries.

For gender, we compared a model with no equality constraints between girls and boys with a model with equality constraints on the path coefficients. The differences in CFI values for the two models for infant height-for-age and infant weight-for-height were both 0.000 , indicating that caregiver education had similar associations with the growth of infant girls and boys through household resources (see Bornstein, Putnick, Lansford, Deater-Deckard, \& Bradley, 2015). 


\section{Follow-up Analyses}

Children aged 0-4-Because the larger scientific community is often interested in how children under 5 fare, we repeated the models in Figure 1 on a larger sample of children from birth through 4 years $(M=1.96, S D=1.38$ years $)$ in 165,666 families from the same 39 countries. The models fit well for this larger group: $\chi^{2}(1)=433.29, p<.001, \mathrm{CFI}=1.00$, $\mathrm{TLI}=.99, \mathrm{RMSEA}=.051,90 \% \mathrm{CI}=.047-.055, \mathrm{SRMR}=.01$, for height-for-age; and $\chi^{2}(1)$ $=293.86, p<.001, \mathrm{CFI}=1.00, \mathrm{TLI}=.99, \mathrm{RMSEA}=.042,90 \% \mathrm{CI}=.038-.046, \mathrm{SRMR}=$. 01 , for weight-for-height. Multiple group models by child age indicated that the parameter estimates were similar for models on 0 - to 2-year-olds and 3- to 4-year-olds, $\Delta \mathrm{CFI}=.002$ for height-for-age and $\Delta \mathrm{CFI}=.003$ for weight-for-height, indicating that the models displayed in Figure 1 apply to the full age range $0-4$ (models are available from the authors).

Stunting and wasting-We chose to focus our models on continuously distributed height-for-age and weight-for-height variables to maximize variance and predictive power. However, policies often target children who are severely stunted and wasted (> $3 S D$ below average on height-for-age and weight-for-height, respectively). Consequently, we recoded height-for-age and weight-for-height into 3 categories: (0) no, $>M$ or $<2 S D$ s below the $M$, (1) moderate, 2-3 SDs below the $M$, and (2) severe, > $3 S D$ s below the $M$. Using the WLSMV estimator in Mplus, we recomputed the models in Figure 1, substituting stunting and wasting for height-for-age and weight-for-height. The models fit well, $\chi^{2}(1)=293.51, p$ $<.001, \mathrm{CFI}=1.00, \mathrm{TLI}=.95, \mathrm{RMSEA}=.050,90 \% \mathrm{CI}=.045-.055$, for stunting; and $\chi^{2}(1)$ $=168.72, p<.001, \mathrm{CFI}=1.00, \mathrm{TLI}=.97, \mathrm{RMSEA}=.038,90 \% \mathrm{CI}=.033-.043$, for wasting. The model coefficients for stunting and wasting were similar to those for heightfor-age and weight-for-height, respectively (models are available from the authors).

\section{Discussion}

Being a child's principal caregiver is challenging even under the best of circumstances; but caregiver responsibilities in conditions of poverty and environmental deprivation can be daunting (Magnuson \& Duncan, 2002). Limited household resources can directly undermine the health of infants and limit what parents can do to promote adequate growth in offspring. Generally low levels of caregiver education and a paucity of household resources reduce infant thriving. This study explored a transmission channel from caregiver education through household resources to infant growth in a large number of low- and middle-income countries. Caregiver education was associated with the availability and use of household resources, and household resources were associated with infant growth, leaving little direct association between caregiver education and infant growth. Furthermore, these associations held controlling for infant feeding and health, were largely similar in low-, medium-, and high-HDI countries, and were the same for girls and boys.

Stunting and wasting reflect multiplicative effects of poor health circumstances. Accordingly, it is important to identify putative pathways through which improvements in individual and environmental circumstances might increase prospects for infants who are generally disadvantaged. Prior research has shown that better educated parents in LMIC make more judicious choices pertaining to health care (Ahmed et al., 2010), thereby 
improving prospects for themselves and their children. Our findings extend this idea to show that more education is related to better availability and utilization of resources more generally, including common household resources and resources needed to foster children's learning, independent of nutrition and basic health status.

Although similar in direction and significance, the magnitudes of associations between caregiver education and household resources varied somewhat across low-, medium-, and high-HDI countries. Caregiver education had stronger relations with quality of housing and material resources in low- and medium-HDI countries than in high-HDI countries.

Furthermore, the percent of variance in the direct association that was mediated by caregiver education ranged from $48 \%$ to $78 \%$ ( $76 \%$ for all countries combined). High-HDI countries may have higher standards of living (e.g., widespread access to electricity, plumbing, public utilities) across all levels of the population, perhaps rendering caregiver education less important to the availability of these resources. In low- and medium-HDI countries, where infrastructure is less accessible, highly educated caregivers may have access to more and better household resources to support their very young children's health and growth.

Of household resources, quality of housing had the largest relation to infant height-for-age and weight-for-height. This association is not surprising because quality of housing included indicators that are likely to affect infant health (e.g., drinking water and sanitation) and nutrition (e.g., refrigeration and cooking facilities). Material resources and learning resources had similar relations to infant height-for-age, but only learning resources were related to infant weight-for-height. The availability of material (e.g., radio, TV, electricity) and learning resources (e.g., books and toys) may be an indication of the wealth of the household; thus, the relation observed could partially reflect access to other resources that also help support infant growth. Material and learning resources also provide infants with opportunities for learning and stimulation, and access to stimulation affects brain growth, with its known relations to good health generally (Farah et al., 2008). Walker et al. (2007) identified cognitive stimulation as one of four areas in urgent need of intervention in LMIC.

\section{Limitations}

Several limitations in the MICS data constrain what can be learned from them. Although the MICS contains an impressive number of inhabitants in a substantial number of LMIC, sample sizes vary across countries. Moreover, not all countries provided all data. However, geographically and demographically stratified nationally representative samples were collected, and trained national civil workers, demographers, and other key stakeholders from participating countries developed and administered the MICS. MICS data also draw from caregiver reports on limited sets of items, many of which are based on binary yes/no responses. Furthermore, MICS indicators are cross-sectional, precluding longitudinal analyses and causal interpretations. Here, we limit our deductions to exploratory hypothesisgenerating associations.

\section{Policy Implications}

Identifying operative antecedents of infant growth would permit policymakers to identify and target effective means to improve infant health and development. The findings we report 
here prompt a policy focus on caregiver educational achievement to promote healthier development in infants and children in the next generation. One possibility is to target future parents in their youth, by augmenting their education, before they start forming a family. In this respect it is disheartening that the proportion of LMIC children in secondary education (tomorrow's parents) is still $<60 \%$, but heartening that the beginning of the 21 st century has witnessed substantial increases in educational attainments: Between 1999 and 2011, the proportion of LMIC children in primary education increased from $80 \%$ to $88 \%$ and in secondary education from $47 \%$ to 59\% (The World Bank, 2013). Studies in sub-Saharan Africa document how dramatic improvements in primary schooling might be achieved, for example, through payment of school fees that include Parent-Teacher Association and community contributions, textbook costs, and sundry charges that may otherwise impede school enrollment. For instance, through cash infusion, public school enrollment in the most economically deprived districts of Ghana increased from 4.2 million to 5.4 million just between 2004 and 2005 (The World Bank, 2013).

Education has meaning. Increases in education improve parents' perspectives on their lives, enhance their own cognitive and literacy skills, and may spill over to increased feelings of mastery and competence in the sense that education helps parents organize their lives and mobilize available resources efficaciously with respect to their childrearing. Our findings suggest that educating current or future caregivers can indirectly affect infant physical growth and health of the next generation of girls and boys and can do so regardless of their country's overall standing on human development.

The Convention on the Rights of the Child (CRC; United Nations General Assembly, 1989) supposes an ecological perspective in stipulating rights, with prominent place given to contexts of development. Furthermore, Implementing Child Rights in Early Childhood (General Comment No. 7; United Nations General Assembly, 2006) states, "Ensuring [child] survival and physical health are priorities" (p. 4). All children have rights to highstandard nutrition and health care, to an environment that supports their thriving, and to nurturing and stimulating caregiving. Our findings on poor housing conditions and limited access to learning resources have clear implications for parents, practitioners, and policymakers. The CRC recognizes that parents and caregivers have the primary responsibility of rearing infants but also that parents require assistance in optimizing environments. Living in poorly constructed homes with inadequate facilities for drinking, cooking, and toileting pose direct threats to infant health, including adequate physical growth. As countries improve infrastructure pertaining to water, sanitation, and health care, growth problems in childhood should remit.

A pernicious fact of inadequately educated parents and low-quality home environments in LMIC is that they contribute to the intergenerational transmission of poverty and reduced quality of life. Because lack of access to household resources contributes to poor health, GDP is reduced at community and societal levels (Qureshi \& Mohyuddin, 2006). Failure to improve GDP then decreases the likelihood of an educated populace and increases the likelihood that low-quality housing will persist into succeeding generations. The well-being of the current generation of infants and the turnover to the next would almost certainly improve with enhanced caregiver education (Walker et al., 2007). Furthermore, 
improvements in infrastructure and access to health care decrease the likelihood that infants will suffer growth deficiencies. These movements toward fulfillment of two key UN MDGs ( 2 and 7 ) have the potential to markedly improve well-being for infants around the globe. However, improvements have not been uniform within or across LMIC. To some extent, upgrades in infrastructure have shifted what matters as regards community resources, parenting practices, and household resources. Broad access to affordable, safe, healthy, and stimulating home environments reduces the effect of caregiver education on infant growth.

\section{Conclusion}

Infants living in LMIC may be affected by inadequate household resources, which are associated with achieved education of primary caregivers. Put another way, having parents (especially mothers) who are better educated might contribute to the likelihood that infants will grow appropriately partly because better educated caregivers command more resources. As growth faltering in early childhood is pronounced, there is need to scale up interventions during the window of opportunity bracketed by the " 1000 days" of prenatal development and infancy. In this light educating current and future parents in LMIC is not an expense, it is an investment.

\section{Acknowledgements}

MHB and DLP were supported by the Intramural Program of the NIH, NICHD. The study sponsor had no role in study design, data collection, data analysis, data interpretation, or writing of the report. We thank B. Gates for stimulating this inquiry and UNICEF and individual countries for collecting the data.

\section{References}

Ahmed S, Creanga AA, Gillespie DG, Tsui AO. Economic status, education and empowerment: implications for maternal health service utilization in developing countries. PloS ONE. 2010; 5(6):e11190. [PubMed: 20585646]

Arbuckle, JL. Full information estimation in the presence of incomplete data. In: Marcoulides, GA.; Schumacker, RE., editors. Advanced structural equation modeling: Issues and techniques. Mahwah, NJ: Erlbaum; 1996. p. 243-277.

Barro RJ, Lee JW. A new data set of educational attainment in the world, 1950-2010. Journal of Development Economics. 2013; 104:184-198.

Bartlett S. Water, sanitation and urban children: the need to go beyond "improved" provision. Environment and Urbanization. 2003; 15(2):57-70.

Bartlett S, Minujin A. The everyday environments of children's poverty. Children Youth and Environments. 2009; 19(2):1-11.

Black RE, Allen LH, Bhutta ZA, Caulfield LE, De Onis M, Ezzati M, Rivera J. Maternal and child undernutrition: global and regional exposures and health consequences. The Lancet. 2008; 371(9608):243-260.

Black RE, Victora CG, Walker SP, Bhutta ZA, Christian P, de Onis M, Uauy R. Maternal and child undernutrition and overweight in low-income and middle-income countries. The Lancet. 2013; 382(9890):427-451.

Bornstein, MH. Children's parents. In: Bornstein, MH.; Leventhal, T., editors. Ecological settings and processes in developmental systems Volume 4 of the Handbook of child psychology and developmental science. Vol. 7e. Hoboken, NJ: Wiley; 2015. p. 55-132.Editor-in-chief: R. M. Lerner

Bornstein MH, Hahn C-S, Suizzo MA, Haynes OM. Mothers' knowledge about child development and childrearing: National and cross-national studies. Unpublished manuscript, National Institutes of Child Health and Human Development. 2001 
Bornstein MH, Putnick DL, Lansford JE, Deater-Deckard K, Bradley R. Gender in low- and middleincome countries. Monograph of the Society for Research in Child Development. 2015

Bradley RH, Putnick DL. Housing quality and access to material and learning resources within the home environment in developing countries. Child Development. 2012; 83(1):76-91. [PubMed: 22277008]

Burchi F. Whose education affects a child's nutritional status? From parents' to household's education. Demographic Research. 2012; 27:681-704.

Cattaneo, MD.; Galiani, S.; Gertler, PJ.; Martinez, S.; Titiunik, R. Housing, health and happiness. World Bank Policy Research Working Paper 4214. 2007 Apr. Retrieved January 31, 2015 from openknowledge.worldbank.org/bitstream/handle/10986/7295/wps421401update.pdf?sequence=1

Checkley W, Buckley G, Gilman RH, Assis AM, Guerrant RL, Morris SS, Mølbak K, ValentinerBranth P, Lanata CF, Black RE. The Childhood Malnutrition and Infection Network. Multicountry analysis of the effects of diarrhoea on childhood stunting. International Journal of Epidemiology. 2008; 37(4):816-830. [PubMed: 18567626]

Cheung GW, Rensvold RB. Evaluating goodness-of-fit indexes for testing measurement invariance. Structural Equation Modeling. 2002; 9(2):233-255.

Cohen, J. Statistical power analysis for the behavioral sciences. Psychology Press; 1988.

Currie J, Moretti E. Mother's education and the intergenerational transmission of human capital: Evidence from college openings. The Quarterly Journal of Economics. 2003; 118(4):1495-1532.

Farah MJ, Betancourt L, Shera DM, Savage JH, Giannetta JM, Brodsky NL, Hurt H. Environmental stimulation, parental nurturance and cognitive development in humans. Developmental Science. 2008; 11:793-801. [PubMed: 18810850]

Frost MB, Forste R, Haas DW. Maternal education and child nutritional status in Bolivia: finding the links. Social Science \& Medicine. 2005; 60(2):395-407. [PubMed: 15522494]

Guryan, J.; Hurst, E.; Kearney, MS. Parental education and parental time with children. National Bureau of Economic Research; 2008. (No. w13993)

Halpenny CM, Koski KG, Valdés VE, Scott ME. Prediction of child health by household density and asset-based indices in impoverished Indigenous villages in rural Panamá. The American Journal of Tropical Medicine and Hygiene. 2012; 86(2):280-291. [PubMed: 22302864]

Herrin WE, Amaral MM, Balihuta AM. The relationships between housing quality and occupant health in Uganda. Social Science \& Medicine. 2013; 81:115-122. [PubMed: 23313496]

Holding P. Adaptation and use of the middle childhood HOME Inventory in Kilifi, Kenya. 2003 Unpublished manuscript.

Hong R, Banta JE, Betancourt JA. Relationship between household wealth inequality and chronic childhood under-nutrition in Bangladesh. International Journal for Equity in Health. 2006; 5(1):110. [PubMed: 16522204]

Hu LT, Bentler PM. Cutoff criteria for fit indexes in covariance structure analysis: Conventional criteria versus new alternatives. Structural Equation Modeling: A Multidisciplinary Journal. 1999; 6(1):1-55.

International Energy Agency. World Energy Outlook 2012: Access to Electricity. Paris: International Energy Agency; 2012.

Leventhal T, Newman S. Housing and child development. Children and Youth Services Review. 2010; 32(9):1165-1174.

MacKinnon, D. Introduction to statistical mediation analysis. New York: Erlbaum; 2008.

Magnuson, KA.; Duncan, GJ. Parents in poverty. In: Bornstein, MH., editor. Handbook of parenting. 2nd ed.. Mahwah, NJ: Erlbaum; 2002. p. 95-121.

Marsh, HW.; Balla, JR.; Hau, K-T. An evaluation of incremental fit indices: A clarification of mathematical and empirical properties. In: Marcoulides, GA.; Schumacker, RE., editors. Advanced structural equation modeling: Issues and techniques. Mahwah, NJ: Erlbaum; 1996. p. 315-353.

Maxwell SE, Cole DA. Bias in cross-sectional analyses of longitudinal mediation. Psychological Methods. 2007; 12(1):23-44. [PubMed: 17402810] 
Motarjemi Y, Käferstein F, Moy G, Quevedo F. Contaminated weaning food: a major risk factor for diarrhoea and associated malnutrition. Bulletin of the World Health Organization. 1993; 71(1):7992. [PubMed: 8440042]

Muthén, LK.; Muthén, BO. Mplus: Statistical analysis with latent variables: User's guide. Los Angeles, CA: Muthén \& Muthén; 2012.

Qureshi HA, Mohyuddin HA. Health status, diseases, and economic development: A cross-country analysis. The Journal of Developing Areas. 2006; 39(2):121-128.

Ruble, DN.; Martin, CL.; Berenbaum, SA. Gender development. In: Kuhn, D.; Siegler, RS.; Damon, W., Series Ed., editors. Handbook of child psychology: Vol. 2. Cognition, Perception, and Language. 6th ed.. Hoboken, NJ: Wiley; 2006. p. 858-932.

Shrout PE, Bolger N. Mediation in experimental and nonexperimental studies: new procedures and recommendations. Psychological Methods. 2002; 7(4):422-445. [PubMed: 12530702]

The World Bank. World Development Indicators: Participation in education. Washington, DC: World Bank; 2013. Retrieved from https://secure.europedagogie.eu:8443/europedagogie.eu/IMG/pdf/ Education_Monde_Unesco_.pdf

UNICEF. Appendix Five: Anthropometric techniques. New York: UNICEF; 2002. Retrieved from http://www.childinfo.org/files/MICS3_Appendix_5_-_Anthropometric_Techniques_060525.pdf

UNICEF/WHO/World Bank. UNICEF-WHO-World Bank Joint Child Malnutrition Estimates. New York: UNICEF; 2013. Geneva: WHO, Washington, DC: The World Bank

United Nations Children's Fund. Multiple Indicator Cluster Survey manual 2005: Monitoring the situation of children and women. New York: UNICEF; 2006. Retrieved from http:// www.childinfo.org/mics3_manual.html

United Nations Development Programme. Human development indices: A statistical update. 2008. Retrieved from http://hdr.undp.org/en/media/HDI_2008_EN_Complete.pdf

United Nations General Assembly. Convention on the rights of the child. New York: United Nations; 1989.

United Nations General Assembly. Convention on the rights of the child: General comment No. 7 (2005). New York: United Nations; 2006.

United Nations. Goal 1. Eradicate extreme poverty and hunger. 2013. Retrieved from http:// www.un.org/millenniumgoals/poverty.shtml

Victora CG, Adair L, Fall C, Hallal PC, Martorell R, Richter L, Sachdev HS. Maternal and child undernutrition: consequences for adult health and human capital. The Lancet. 2008; 371(9609): 340-357.

Wachs TD. Commentary: Mechanisms linking parental education and stunting. The Lancet. 2008; 371(9609):280-281.

Wagstaff A, Bustreo F, Bryce J, Claeson M. WHO., World Bank., Child Health and Poverty Working Group. Child health: reaching the poor. American Journal of Public Health. 2004; 94(5):726-738. [PubMed: 15117689]

Walhovd KB, Fjell AM, Brown TT, Kuperman JM, Chung Y, Hagler DJ, Gruen J. Long-term influence of normal variation in neonatal characteristics on human brain development. Proceedings of the National Academy of Sciences. 2012; 109(49):20089-20094.

Walker SP, Wachs TD, Meeks Gardner J, Lozoff B, Wasserman GA, Pollitt E, Carter JA. Child development: risk factors for adverse outcomes in developing countries. The Lancet. 2007; 369(9556):145-157.

Wilcox, B.; Kline, KK., editors. Gender and parenthood: Biological and social scientific perspectives. New York: Columbia University Press; 2013.

World Health Organization (WHO). WHO global database on child growth and malnutrition. Geneva: World Health Organization; 1997.

World Health Organization (WHO). Complementary feeding: Report of the global consultation: Summary of guiding principles. Geneva: WHO; 2002.

World Health Organization (WHO). WHO child growth standards: Length/height-for-age, weight-forage, weight-for-length, weight-for-height and body mass index-for-age: Methods and development. Geneva: World Health Organization; 2006. 
WHO/UNICEF. Progress on drinking water and sanitation: Special focus on sanitation. Geneva: World Health Organization; 2008.

WHO/UNICEF. WHO child growth standards and the identification of severe acute malnutrition in infants and children. A Joint Statement by the World Health Organization and the United Nations Children's Fund. Geneva: WHO; 2009. New York: UNICEF

Yongsi HBN. Suffering for water, suffering from water: Access to drinking-water and associated health risks in Cameroon. Journal of Health, Population, and Nutrition. 2010; 28(5):424-435. 
(1)

Caregiver Education



(2)



Figure 1.

Path analyses of caregiver education predicting two indexes of infant physical growth through three indexes of household resources.

Note. Standardized correlations among household resources were .67 between quality of housing and material resources, .41 between quality of housing and learning resources, and . 35 between material and learning resources in both models. All standardized path coefficients were significant at $p<.05$. (1) Model Fit: $\chi^{2}(1)=218.29, p<.001$. CFI $=.999$. $\mathrm{TLI}=.989$. RMSEA $=.043 ; 90 \% \mathrm{CI}=.038-.048$. SRMR $=.009 .(2)$ Model Fit: $\chi^{2}(1)=$ $234.96, p<.001 . \mathrm{CFI}=.999 . \mathrm{TLI}=.988 . \mathrm{RMSEA}=.045 ; 90 \% \mathrm{CI}=.040-.049 . \mathrm{SRMR}=$. 009 . 
(1)

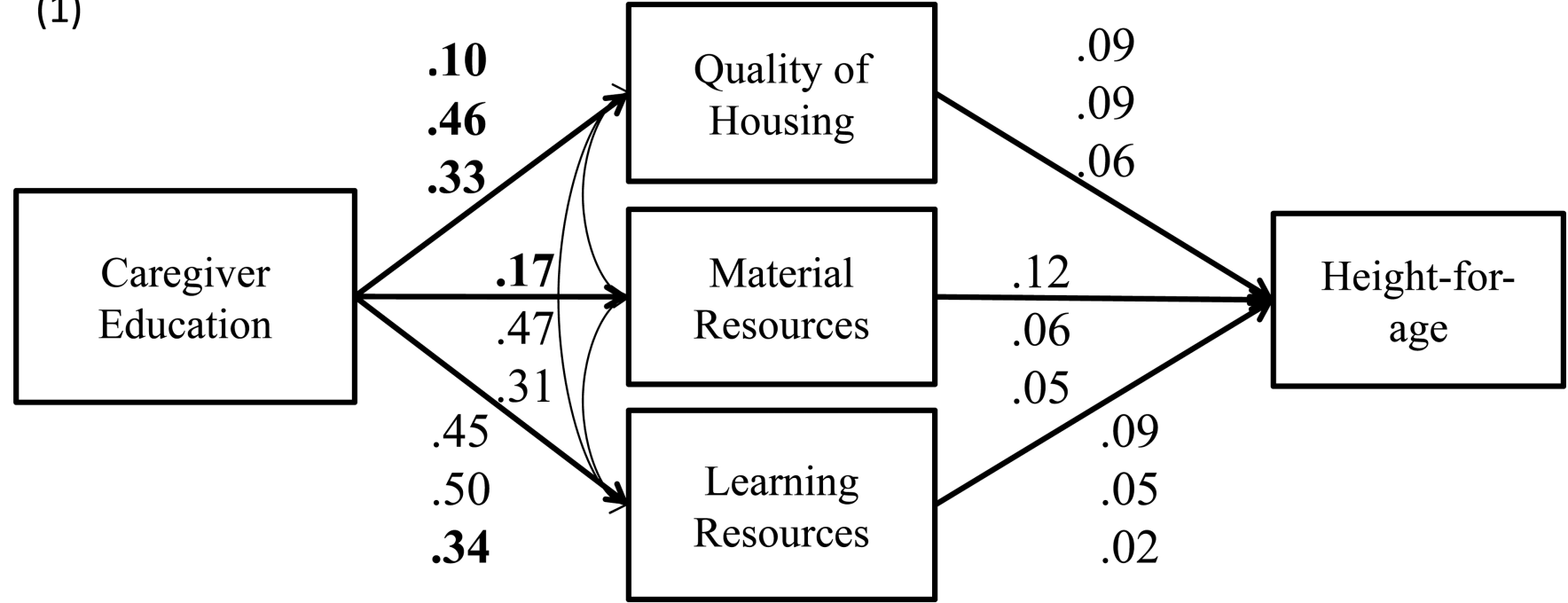

(2)

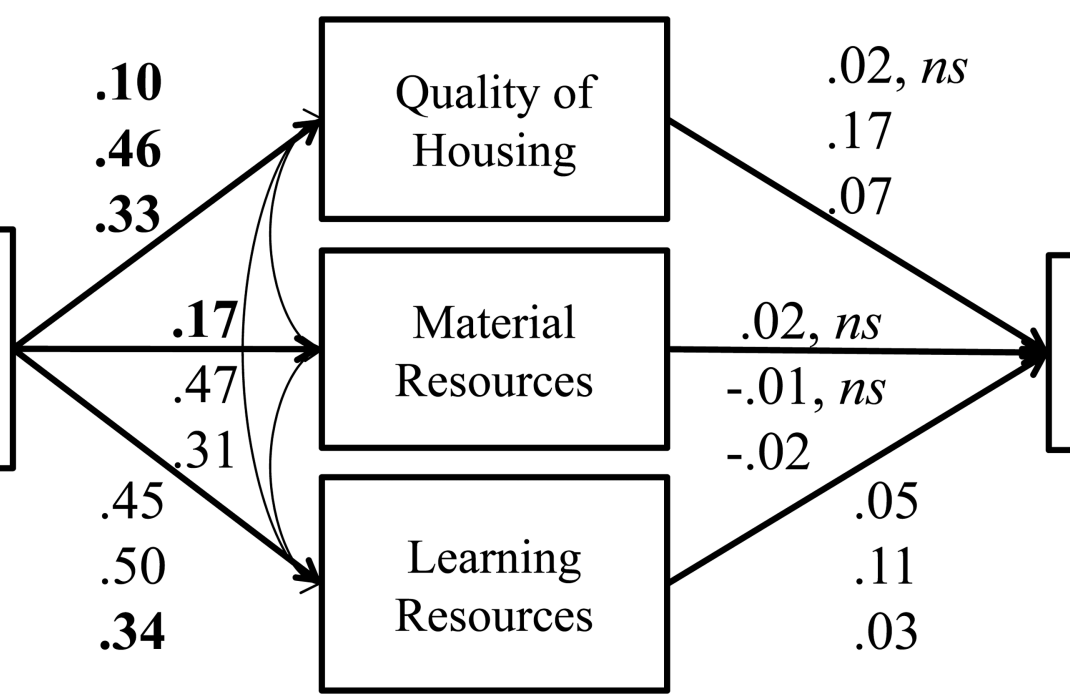

Weight-for-

Figure 2.

Path analyses of caregiver education predicting two indexes of infant physical growth through three indexes of household resources by HDI group.

Note. Standardized path coefficients for High-HDI are on the top, Medium-HDI are in the middle, and Low-HDI are on the bottom. Standardized correlations among household resources were .60 between quality of housing and material resources, .24 between quality of housing and learning resources, and .27 between material and learning resources in both models. All coefficients were significant at $p<.05$ unless otherwise noted. Bolded coefficients were significantly different from other groups and were released in multiplegroup models. 


\section{Table 1}

Country, sample sizes, and HDI scores

\begin{tabular}{|c|c|c|}
\hline Countries & $n$ & HDI \\
\hline \multicolumn{3}{|l|}{ High HDI } \\
\hline Trinidad and Tobago & 602 & .833 \\
\hline Montenegro & 516 & .822 \\
\hline Serbia & 2,000 & .821 \\
\hline Belarus & 1,779 & .817 \\
\hline Macedonia & 2,147 & .808 \\
\hline Albania & 546 & .807 \\
\hline Kazakhstan & 2,472 & .807 \\
\hline Bosnia \& Herzegovina & 1,710 & .802 \\
\hline \multicolumn{3}{|l|}{ Medium HDI } \\
\hline Thailand & 5,400 & .786 \\
\hline Ukraine & 1,651 & .786 \\
\hline Belize & 425 & .771 \\
\hline Jamaica & 785 & .771 \\
\hline Suriname & 1,155 & .770 \\
\hline Georgia & 1,076 & .763 \\
\hline Syrian Arab Republic & 5,443 & .736 \\
\hline Guyana & 1,257 & .725 \\
\hline Mongolia & 2,091 & .720 \\
\hline Vietnam & 1,497 & .718 \\
\hline Uzbekistan & 2,756 & .701 \\
\hline Kyrgyzstan & 1,584 & .694 \\
\hline Vanuatu & 928 & .686 \\
\hline Tajikistan & 2,238 & .684 \\
\hline Laos & 2,189 & .608 \\
\hline Yemen & 1,906 & .567 \\
\hline Mauritania & 4,747 & .557 \\
\hline Ghana & 1,900 & .533 \\
\hline Bangladesh & 17,055 & .524 \\
\hline Cameroon & 3,510 & .514 \\
\hline Djibouti & 1,095 & .513 \\
\hline \multicolumn{3}{|l|}{ Low HDI } \\
\hline Nigeria & 9,058 & .499 \\
\hline Togo & 2,406 & .479 \\
\hline Gambia & 3,977 & .471 \\
\hline Côte d' Ivoire & 4,996 & .431 \\
\hline Guinea-Bissau & 3,431 & .383 \\
\hline Burundi & 3,687 & .382 \\
\hline Burkina Faso & 3,219 & .372 \\
\hline
\end{tabular}

Infancy. Author manuscript; available in PMC 2016 July 01. 


\begin{tabular}{lcc}
\hline Countries & $\boldsymbol{n}$ & HDI \\
\hline Mozambique & 6,497 & .366 \\
Central African Republic & 5,205 & .352 \\
Sierra Leone & 2,954 & .329 \\
\hline
\end{tabular}

Note. HDI scores are reproduced from UNDP (2008). 


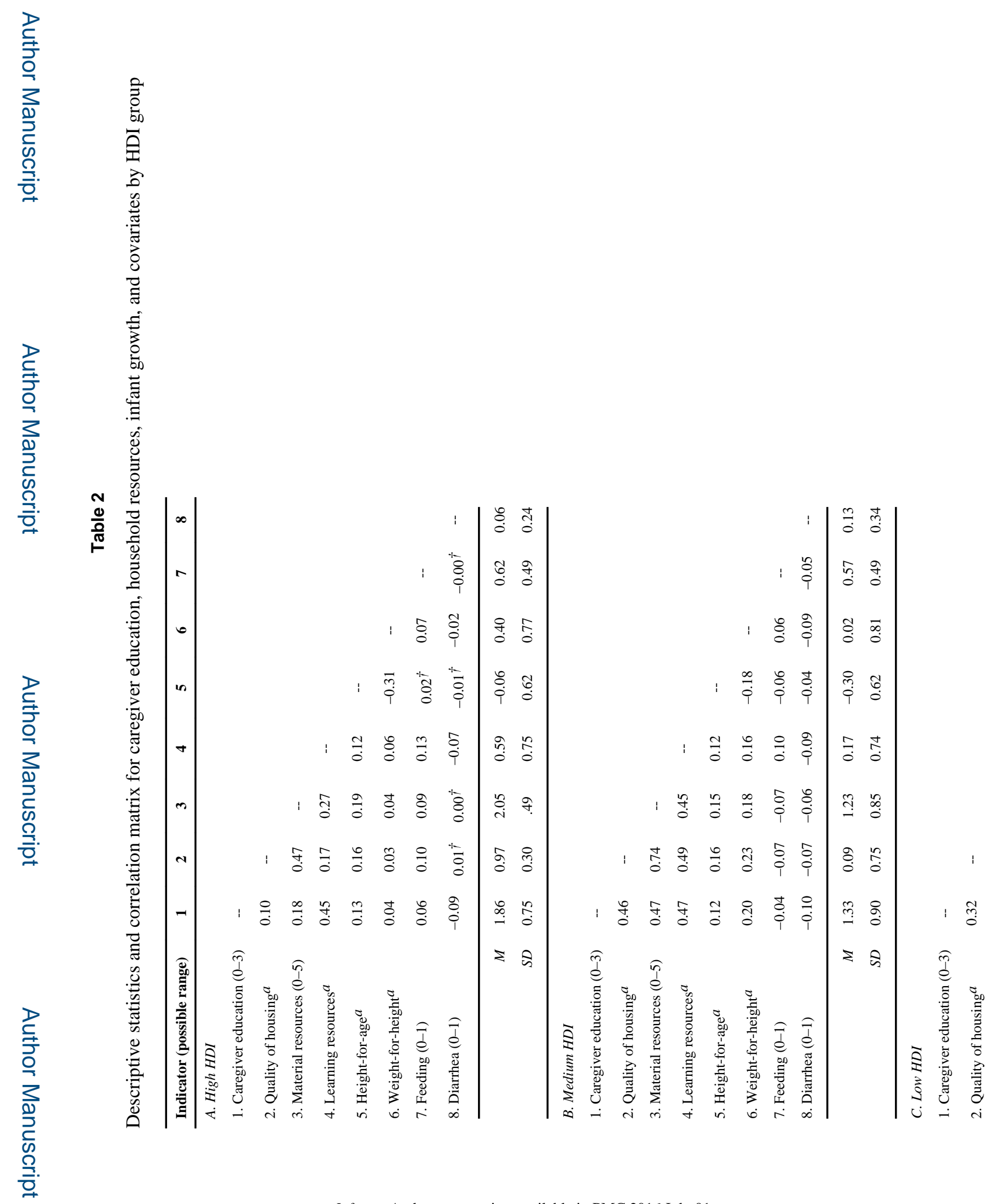

Infancy. Author manuscript; available in PMC 2016 July 01. 


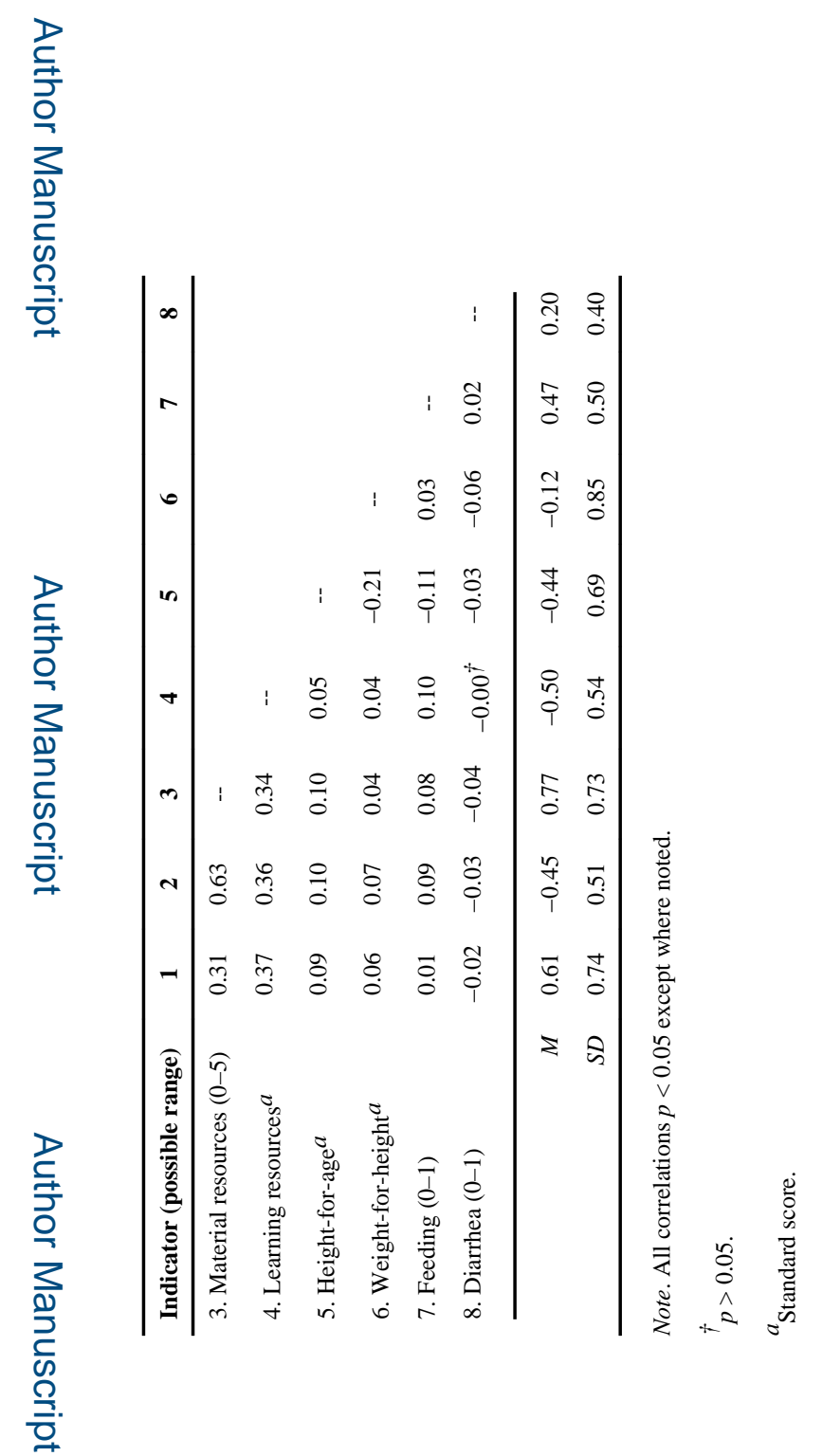

Infancy. Author manuscript; available in PMC 2016 July 01. 